\title{
TRANSEXUALIDADE: CORPO, SUBJETIVIDADE E SAÚDE COLETIVA
}

\author{
Márcia Arán \\ Universidade do Estado do Rio de Janeiro, Rio de Janeiro, Brasil
}

Sérgio Zaidhaft

Hospital Universitário Clementino Fraga Filho, Rio de Janeiro, Brasil

Daniela Murta

Universidade do Estado do Rio de Janeiro, Rio de Janeiro, Brasil

\begin{abstract}
RESUMO: O artigo discute o atendimento a pacientes transexuais na rede pública de saúde, a partir de uma pesquisa exploratória realizada no Hospital Universitário Clementino Fraga Filho, da Universidade Federal do Rio de Janeiro (HUCFF/UFRJ), com transexuais que procuraram atendimento com o objetivo de realização de cirurgia de transgenitalização. Observa-se que a transexualidade se caracteriza por uma condição de intenso sofrimento. Esta experiência se dá não apenas por uma percepção de não pertencimento ao sexo dito biológico, mas, sobretudo, pela precariedade social proveniente da não aceitação desta condição por parte da normatividade cultural vigente. Para além das questões subjetivas mais singulares, esta problemática revela fundamentalmente a insuficiência da nossa categorização sexual, e demonstra como os sistemas classificatórios de sexo e gênero utilizados pelos especialistas se constituem através de uma operação de exclusão. Sendo assim, considera-se que mesmo que, conjunturalmente, o diagnóstico de transtorno de identidade de gênero possibilite o acesso ao tratamento público, não se pode deixar de questionar os efeitos desta normalização.
\end{abstract}

PALAVRAS-CHAVE: Transexualidade; transexualismo; sexualidade; gênero; medicina; subjetividade.

\section{TRANSEXUALITY: BODY, SUBJECTIVITY AND COLLECTIVE HEALTH}

ABSTRACT: The article discusses health assistance given to transexual patients at public hospitals, based on in-house research carried out at the Hospital Universitário Clementino Fraga Filho of the Universidade Federal do Rio de Janeiro (HUCFF/UFRJ), where these patients seek medical assistance with the purpose of having transgenital surgery performed. Observations demonstrate that transexuality is characterized by a condition of severe suffering. This is an experience that comes from the individual's awareness of not pertaining to its biological gender, but, above all, by the social unsafeness that comes from society not accepting this condition due to current cultural norms. Beyond the boundaries of the more singular and subjective issues, this situation reveals, in profound detail, the insufficiency of our sexual categorization, and illustrates how the categorization system of sex and gender utilized by specialists is based on exclusion. Hence it is argued that even within the context, the diagnosis of gender identification disorder permitting the access to public treatment, one ought not to cease questioning the effects of this normalization.

KEYWORDS: Transsexuality; transexualism; sexuality; gender; medicine; subjectivity.

Em 1997, o Conselho Federal de Medicina (CFM), através da Resolução 1482/97, aprovou a realização de cirurgia de transgenitalização nos hospitais públicos universitários do Brasil. Esta resolução considera que tal cirurgia tem como motivo essencial uma "intenção de beneficência", baseada em dois princípios: o primeiro deles terapêutico, ou seja, "a busca da integração entre o corpo e a identidade sexual psíquica do interessado"; e o segundo refere-se aos princípios de autonomia e justiça. A con- firmação do diagnóstico de transexualismo torna-se condição do tratamento, sendo que a cirurgia só poderá ser realizada após acompanhamento psiquiátrico por, no mínimo, dois anos. A partir daquele ano, vários serviços interdisciplinares especializados foram organizados, motivados, principalmente, pela demanda de transexuais que procuraram o atendimento público após a divulgação desta resolução pela mídia.

Em 2002, a Resolução 1652 do CFM revogou a anterior. A partir daquela, fica resolvido que as cirurgias para 
adequação do fenótipo masculino para feminino poderão ser praticadas em hospitais públicos ou privados, independentemente da atividade de pesquisa. No caso da neofaloplastia e/ou procedimentos complementares, a realização se manteve condicionada à prática em hospitais universitários ou públicos adequados para a pesquisa.

Em recente jornada, intitulada "Transexualidade e Saúde: a assistência pública no Brasil”, promovida pelo Instituto de Medicina Social da Universidade Estadual do Rio de Janeiro (IMS/UERJ) e pela Coordenação de Saúde Mental do Ministério da Saúde, observamos que os serviços que prestam assistência a transexuais são bem distintos. Embora todos se constituam numa equipe multidisciplinar, a implantação dos programas foi bastante lenta e sofreu muitas resistências institucionais.

É importante salientar que o debate relativo à assistência a transexuais tem sido pauta do Comitê Técnico Saúde da População de Gays, Lésbicas, Transgêneros e Bissexuais do Ministério da Saúde. Segundo Lionço (2006), este grupo foi criado a partir de demanda específica do Conselho Nacional de Combate à Discriminação vinculado à Secretaria Especial de Direitos Humanos que, em 2003, levantou à demanda da proposição de ações políticas que viessem atender às especificidades de populações historicamente estigmatizadas e excluídas dos benefícios estatais.

Pode-se considerar que a realização da I Jornada sobre "Transexualidade e Saúde...": A assistência pública no Brasil", em 2005, a organização do Coletivo de Transexuais, no início de 2006, e, principalmente, a convocação da reunião sobre "O processo transexualizador no SUS”, em fevereiro de 2006, explicitaram a importância da gestão de políticas públicas para transexuais no Brasil e a necessidade da inclusão da cirurgia de redesignação sexual no SUS. No entanto, em primeiro lugar, entendemos que o princípio da integralidade deve ser garantido tanto nas praticas quanto na oferta dos serviços de saúde. Em segundo lugar, mesmo considerando a importância da resolução do CFM (1997), é importante salientar a necessidade da psiquiatrização da transexualidade como condição de acesso à saúde pública no Brasil. Desta forma, propomos uma breve discussão sobre o diagnostico de "transtorno de identidade de gênero".

\section{O dispositivo da transexualidade}

$\mathrm{O}$ acontecimento que marca o nascimento do fenômeno da transexualidade na nossa era é a intervenção praticada por Christian Hamburger, na Dinamarca, em 1952, num jovem de 28 anos chamado George Jorgensen, ex-soldado do exército norte-americano. No ano seguinte, Harry Benjamin (1966/1999), a partir deste evento, cria o conceito de transexualismo. Apoiado nos avanços dos estudos biológicos do século XX, em especial os estudos genéticos, o autor propõe que não haveria uma divisão absoluta entre "masculino" e "feminino", sendo inadequada a determinação do sexo do indivíduo baseada puramente nas diferenças anatômicas. Para ele, o sexo seria composto por diversos componentes cromossômico, genético, anatômico ou morfológico, genital, gonádico, legal, germinal, endócrino (hormonal), psicológico e social -, sendo a predominância de um destes fatores o que vai definir o sexo do indivíduo, em conjunto com a influência do meio social sobre o comportamento. Ao mesmo tempo, destaca que, exceto o sexo genético, esses "tipos de sexo" não são fixos e podem ser modificados através de tratamentos hormonais ou procedimentos cirúrgicos.

A partir desta teorização, o autor criou a Escala de Orientação Sexual (Sex Orientation Scale - SOS), um guia diagnóstico através do qual seria possível avaliar a discordância entre os sexos, principalmente a incompatibilidade entre os componentes psicossociais e biomorfológicos. Tal escala tornou-se um marco na conceituação do transexualismo pela possibilidade de esquematizar a diferença entre transexuais, travestis e homossexuais.

Um aprimoramento deste raciocínio tornou-se possível com a contribuição de John Money, que passou a preconizar uma separação entre o "sexo real" - ancorado na biologia e na "natureza" - e o registro subjetivo do gênero, estabelecido através da educação e das influências culturais (Castel, 2003).

Outra referência importante para a definição de transexualismo são as teses de Robert Stoller (1982), psiquiatra e psicanalista, que descreveu e teorizou de forma detalhada a experiência transexual. Para ele, a definição de transexualismo se baseia principalmente em três aspectos: (a) um sentimento de identidade permanente, uma crença (no caso do transexualismo masculino) numa essência feminina sem ambigüidades, (diferentemente do transvestismo, por exemplo); (b) uma relação com o pênis vivida "como horror", não existindo nenhuma forma de investimento libidinal; (c) uma especificidade na relação com a mãe que o autor chama de simbiose. Porém, o autor ressalta que esta relação não pode ser considerada psicotizante, principalmente porque a capacidade de integração social destas pessoas permanece intacta.

Duas grandes linhas teóricas - uma endocrinológica e outra psicossocial - foram produzidas ao longo do século XX, na tentativa de explicar a questão da transexualidade, gerando repercussões importantes. A primeira delas é a apropriação do fenômeno transexual pela medicina através da proposição de tratamentos direcionados a transexuais, e, a segunda, como demonstra Castel (2003), é a criação de um problema médicolegal, visto que esse tipo de intervenção médica, que estava acontecendo de forma crescente, não era permitido 
em todos os países e estava gerando pedidos de redefinição do sexo civil. Diante disso, era preciso que as redesignações sexuais estivessem inseridas em processos terapêuticos formais e que os procedimentos fossem normatizados (Murta, 2007).

A partir destas premissas, Norman Fisk, em 1973, fundamenta uma nosografia psiquiátrica para o transexualismo, ancorada fundamentalmente num autodiagnóstico. Em seguida, o transexualismo é incorporado à categoria psiquiátrica de "Disforia de Gênero" que incluía, além desta condição, outras "enfermidades" ligadas à identidade de gênero. Esta denominação, que designa a insatisfação decorrente da discordância entre o sexo biológico e a identidade sexual de um indivíduo, trazia a descrição da experiência transexual e apontava como a única possibilidade de tratamento a realização da cirurgia de conversão sexual e a utilização de hormônios. Segundo Castel (2003, p. 90), essa invenção de um "híbrido psiquiátrico-sociológico" tinha como objetivo responder a tais necessidades funcionais sem qualquer ambição de construir uma nosografia da disforia de gênero.

Outro conjunto de trabalhos bastante referidos neste debate são aqueles realizados pela tradição da psicanálise lacaniana, principalmente Henry Frignet (1999, 2000), M. Czermak (1982), Joël Dor (1991) e Contardo Calligaris (1989). Nestas teorias destaca-se a relação entre a transexualidade e a compreensão lógica e estrutural da psicose. Cabe salientar que o próprio Lacan teria tido a oportunidade de encontrar "Henry", em 1952, paciente transexual de Jean Delay, e constatar "a dificuldade de realizar uma psicoterapia com transexuais", já que estes, segundo o autor, não a desejavam e não pareciam ter “conflitos psíquicos” (Castel, 2003, p. 372).

Para estes autores, sobressai o fato de que os transexuais masculinos não se identificam com "uma mulher" propriamente dita, mas sim com "a mulher", na medida em que esta posição é idealizada e vivida como plenitude. O que se destaca nesta teoria é a observação clínica de que importa mais a aparência de "ser" mulher, do que a possibilidade de "ter" relações sexuais. Assim, diferentemente da neurose e da perversão, os transexuais não teriam acesso à castração dita simbólica, o que, em última instância, os aproximaria da psicose. A partir destas suposições, alguns autores são bastante reticentes em relação à realização da cirurgia, porém outros destacam a importância que esta pode adquirir na organização subjetiva.

Ainda outra possibilidade teórica referida no campo da psicanálise é pensar o transexualismo como pertencendo a um grupo de casos ditos limites, os quais se situam ao mesmo tempo entre a neurose e a psicose. Desta forma, estes estados poderiam ser considerados uma "doença do narcisismo", tal como sugere Chiland (2003). A linha geral dos trabalhos parte da hipótese da existência de uma relação de objeto "pré-genital" bem distinta da psicótica, mas muito diferente da relação objetal neurótica, sendo que a relação com o Édipo permanece fragmentária e prescinde do recalque como recurso organizador.

Nas diversas teorias que abordam esta questão parece haver um aspecto consensual: o de que na transexualidade haveria uma incoerência entre sexo e gênero. Sendo que o que define o diagnóstico de transexualismo é uma concepção normativa seja dos sistemas de "sexo-gênero", seja do dispositivo "diferença sexual". Ambas estão fundadas numa matriz binária heterossexual que se converte em sistema regulador da sexualidade e da subjetividade (Arán, 2006). Apesar de sua importância, elas não dão conta do que na cultura contemporânea se apresenta como experiência transexual.

Em geral, parte-se do pressuposto de que sexo é algo definido pela natureza, fundamentado no corpo orgânico, biológico e genético, e de que o gênero é algo que se adquire através da cultura. Esta compreensão, por um lado determinista e, por outro, construtivista, restringe em muito a possibilidade de compreensão da transexualidade. Este tipo de raciocínio já foi bastante debatido por autores como Michel Foucault e Judith Butler. Segundo Foucault (1990/1993), o dispositivo da sexualidade na modernidade só pode ser compreendido através dos mecanismos de poder e saber que lhes são intrínsecos. Assim, sexo é o resultado complexo de uma experiência histórica singular e não uma invariante passível de diversas manifestações.

O termo "dispositivo" aparece na obra de Foucault nos anos 70 e designa inicialmente os operadores materiais do poder, ou seja, as técnicas, as estratégias e as formas de sujeição. É importante destacar que a concepção foucaultiana do poder considera que este não atua simplesmente oprimindo ou dominando as subjetividades, mas opera de forma imediata na sua construção. Assim, o caráter formativo ou produtivo do poder estaria totalmente vinculado aos mecanismos de regulação e disciplina que ele instaura e procura conservar (Peixoto Júnior, 2004). O que faz com que os dispositivos reguladores que formam o sujeito do gênero sejam os mesmos responsáveis pela produção da sujeição (Arán \& Peixoto Júnior, no prelo) Assim, o poder problematizado como biopoder, seria antes algo que circula, que funciona em rede, fazendo com que o indivíduo não seja o outro do poder, mas um dos seus primeiros efeitos. A principal forma de exercício do poder que aparece na passagem do século XVIII para o século XIX é a do regime disciplinar, o qual produz um discurso que não é o da lei ou da regra jurídica, mas aquele das ciências humanas que se constituirá como norma. Esta normatividade opera de forma imanente às práticas históricas e sociais produzindo efeitos duradouros de territorialização no campo subjetivo. Atuando como ideal regulador, ela estabelece fronteiras entre determinadas práticas tidas como inteligíveis, 
lícitas e reconhecíveis e outras consideradas ininteligíveis, ilícitas e abjetas, as quais constituem o território dos anormais (Foucault, 1999).

Da mesma forma, gênero não é uma construção social imposta a uma matéria anteriormente determinada (o sexo), e sim um efeito performático que possibilita a constituição e o reconhecimento de uma trajetória sexuada, a qual adquire uma estabilidade em função da repetição e da reiteração de normas. Assim, é importante pensar através de que normas reguladoras se materializam os sistemas "sexo-gênero" (Butler, 1993).

Seguindo este raciocínio, os efeitos de gênero, ou mesmo de corpos, entendidos como produção de subjetividades, emergem na modernidade através da reiteração da matriz heterossexual constituída ao mesmo tempo pela dominação masculina e pela exclusão da homossexualidade. A força da normatização se dá justamente pelo recalque, pelo repúdio ou mesmo pela foraclusão deste território que deve permanecer inteligível, fora das possibilidades de reconhecimento e de simbolização (Arán, 2006).

Porém, se as normas de gênero são históricas e contingentes, e não essenciais ou estruturais, a postulação de um "verdadeiro sexo" ou de uma "verdade sobre o gênero" revela antes uma ficção reguladora. - uma forma de organização do social. Além disso, se para que esta ficção permaneça é necessário uma repetição reiterativa, podemos pensar que a aproximação de um ideal de gênero - masculino ou feminino - nunca é de fato completa, e que os corpos nunca obedecem totalmente às normas pelas quais sua materialização é fabricada. Neste sentido, é justamente pelo fato de a instabilidade das normas gênero estarem abertas à necessidade de repetição do mesmo que a lei reguladora pode ser reaproveitada numa repetição diferencial.

Assim, segundo Butler, esta tensão paradoxal nos permite compreender que se o gênero é uma norma, ele também pode ser fonte de resistência. Desta forma, uma concepção normativa de gênero pode desconstruir a subjetividade de uma pessoa, destruindo gradativamente a capacidade de ela persistir em uma vida considerada viável ou até vivível. Porém, a experiência de desconstrução de uma restrição normativa pode também inaugurar uma nova construção de si, permitindo uma mudança, um alargamento de fronteiras e novos modos de vida. Porém, como a maioria das pessoas não pode viver sem ser em parte reconhecido como humano, então o reconhecimento do sexo e do gênero é o que permite a possibilidade de sua existência.

Neste sentido, tornam-se imprescindíveis estudos empíricos e teóricos que permitam o deslocamento da transexualidade deste território de patologização. Com este objetivo, relatamos a experiência clínica e institucional do Hospital Universitário Clementino Fraga Filho (HUCFF) da UFRJ.

\section{A experiência do Hospital Universitário da UFRJ}

Em novembro de 1997, uma paciente procurou o Serviço de Endocrinologia do HUCFF, dizendo ter conhecimento da Resolução do CFM sendo, então, encaminhada ao Serviço de Psicologia Médica e Saúde Mental. Vale ressaltar que não tínhamos conhecimento desta Resolução, nem possuíamos qualquer experiência relativa a esta questão. Desde então, iniciamos um trabalho de assistência a esta clientela que resultou na organização do Programa Interdisciplinar de Assistência a Pacientes Transexuais e Cirurgia de Transgenitalização do HUCFF, o qual se encontra no momento em avaliação e reestruturação.

De 1997 a 2004, foram atendidas dezesseis pessoas, encaminhadas por outros serviços do próprio hospital, ou indicações realizadas pelas próprias pacientes que já se encontravam em atendimento. Destas, quinze confirmaram a condição transexual, e uma, encaminhada com a hipótese de hermafroditismo, teve seu diagnóstico de transexualismo posteriormente confirmado. Além do atendimento no ambulatório de saúde mental, foram acompanhadas pela urologia, endocrinologia e genética. Do total de quinze transexuais, foram realizadas quatro cirurgias, houve uma desistência, três abandonos, uma recusa de inclusão no programa por ser menor de idade, uma veio ao programa já operada em outro país (visando laudo psiquiátrico para troca de nome), e seis pacientes encontram-se na fila de espera.

Tendo como objetivo a compreensão do dispositivo da transexualidade nas práticas de saúde, assim como um estudo sobre a diversidade das narrativas transexuais, realizamos uma pesquisa exploratória com 16 pacientes atendidos no HUCFF, nos anos de 2003 e 2004 . Conforme explicitado acima, o contato inicial com os transexuais se deu num contexto assistencial, mais precisamente em psicoterapia individual e em grupo realizada no ambulatório. Este contato permitiu não apenas uma delimitação do campo a ser pesquisado, como também a elaboração de um roteiro para a realização de entrevistas semiestruturadas com pacientes transexuais masculinos atendidos no ambulatório, mediante a apresentação e assinatura do termo de consentimento livre e esclarecido.

A faixa etária da maioria das pacientes é de 20 a 40 anos. Todas adotaram e se apresentam com um nome feminino, o qual na maioria das vezes é uma adaptação do nome jurídico. A maior parte das entrevistadas é solteira, sendo que uma, no momento da entrevista, relata ter um namorado fixo, e quatro vivem em regime de concubinato. Apresentaremos a seguir, a partir da análise de conteúdo das informações obtidas nas entrevistas, algumas questões que consideramos relevantes para a dis- 
cussão sobre o dispositivo da transexualidade nas práticas de saúde e a diversidade das narrativas transexuais.

\section{Demanda pela Cirurgia de Transgenitalização}

As pacientes, denominadas aqui no feminino por ser esta sua apresentação e seu desejo, chegam ao hospital com uma clara demanda em relação à cirurgia de transgenitalização. Apesar do sentimento de pertencimento ao gênero feminino se manifestar, na maioria dos casos, desde a infância, e o desejo de transformação corporal geralmente a partir da adolescência, é importante ressaltar que somente nesta última década houve maior procura pelo atendimento. $\mathrm{O}$ principal aspecto que observamos, no que se refere a esta demanda, é a certeza de pertencimento ao gênero feminino e a importância da realização da cirurgia. Perguntadas sobre o motivo da procura de tratamento cirúrgico, observamos os seguintes relatos:

É porque eu não me penso neste corpo . . . Embora eu reconheça que biologicamente sou do sexo masculino, para mim eu não sou homem. Foi isso que me fez procurar ajuda, eu vivia entrando em depressão . . . Eu só quero levar a minha vida normalmente, sem esses problemas. Ser um ser humano normal, ter os direitos que eu não tenho. (Roberta, 33 anos).

"Eu sinto necessidade de fazer essa cirurgia, eu estou com um espírito montado num corpo que não é meu, então eu não me sinto bem" (Maria, 41 anos).

Eu quero fazer a cirurgia, veja bem, eu me sinto uma supermulher. Eu não tiro meu chapéu para mulher nenhuma. Eu sou super feliz comigo mesma, mas, na realidade, eu tenho uma coisa que me incomoda. Me incomoda porque não tem nada a ver comigo fisicamente, não tem nada a ver comigo psicologicamente. (Priscila, 36 anos).

Nota-se que a demanda em relação à cirurgia se constitui basicamente pelo desejo de readequação do corpo sexuado ao gênero. Porém, se inicialmente esta demanda se insere num desejo de adaptação à norma heterossexual (fortemente influenciada pelos profissionais médicos e psis), o acompanhamento cotidiano da diversidade das trajetórias sexuais e subjetivas nos permitiram perceber que não necessariamente "todas" as transexuais desejam a extirpação do pênis e a construção do canal vaginal para a realização do sexo genital "normal". Várias já estabelecem uma relação sexual e afetiva satisfatória, sendo a cirurgia apenas um entre outros atributos para a construção do gênero. Neste sentido, para algumas pessoas "a cirurgia é imprescindível", outras "podem esperar" e ainda outras "podem desistir" da cirurgia sem "deixarem de ser transexuais". Assim, é importante estabelecermos um tempo para o esclarecimento sobre esta demanda de realização da cirurgia e as suas conseqüências.

\section{Relato de Intenso Sofrimento Psíquico}

Todas as pacientes relatam uma condição de intenso sofrimento psíquico, que aparece sob a forma de tentativas de suicídio, depressão, transtornos alimentares e angústia das mais diversas formas o que é provocado não apenas pelo conflito de não pertencimento ao sexo biológico como também pelas inúmeras consequiências sociais intrínsecas a esta condição. A psiquiatria costuma descrever estas experiências como co-morbidade. Porém, não podemos perder de vista em que contexto estes sintomas aparecem, já que na transexualidade o risco de patologização de um problema social está sempre presente.

Eu já pensei em suicídio várias vezes. Eu tenho entrado em muito desespero por causa disso [dificuldade de arranjar emprego]. Eu acho que mesmo operando ainda vão continuar os problemas por causa da mudança de nome. Eu vou vivendo a minha vida, entro em depressão, saio da depressão... eu não sei até quando vou conseguir sair da depressão. (Roberta, 33 anos).

Isso me levou a crises de histeria ... entrei em anorexia . . . eu tava superdeprimida, com crise de bulimia. Eu queria continuar vivendo com a ilusão de que de repente 'ah, você é um hermafrodita e vamos ter que te operar às pressas' . . . Já pensei até em colar [o pênis] com superbonder. É lógico que eu não faço porque não sou louca, mas já pensei. Já cheguei a usar esparadrapo para prender e ficar o dia inteiro, não podia fazer xixi. (Aline, 34 anos).

Eu me sentia revoltada porque eu não conseguia me sentir nem uma coisa nem outra. Teve uma vez que eu fui parar no hospital psiquiátrico . . . acho que eu tive uma crise de identidade, eu ficava confusa com quem eu era com quem eu não era. (Gabriela, 25 anos, desistiu da cirurgia ao longo do tratamento).

A certeza quanto ao pertencimento ao gênero oposto, a qual às vezes se expressa pela crença numa identidade fixa, se repete no cotidiano do atendimento a pacientes transexuais. É evidente que o acolhimento e o reconhecimento deste desejo ou desta crença, sem dúvida, têm uma função terapêutica, para não dizer existencial. Porém, a transexualidade não necessariamente fixa uma posição subjetiva. Talvez o mais importante, nestes casos, seja deslocar a manifestação empírica e social da transexualidade da necessidade de traduzi-la imediatamente numa estrutura ou num modo de funcionamento específico, o que nos permitiria escapar da psiquiatrização ou mesmo da violência da interpretação psicanalítica. A experiência transexual, neste sentido, comportaria várias formas singulares de subjetivação. É importante levarmos sempre em conta que "certos tipos de "identidade de gênero' parecem ser meras falhas do desenvolvimen- 
to, ou impossibilidades lógicas, porque não se conformam às normas da inteligibilidade cultural vigente" (Butler, 2003, p. 64).

\section{Experiência de pertencimento ao gênero feminino}

Alguns atributos culturais considerados característicos de feminilidade às vezes são ressaltados com o objetivo claro de convencimento desta condição, o que evidencia uma crença numa essência feminina, a qual é reforçada pelos códigos culturais vigentes. É importante destacar que esta percepção ocorre desde a infância, sendo que na maioria das vezes é na adolescência que esta condição começa a ser vivida como conflito.

... desde os sete anos eu já me sentia diferente dos outros meninos. Eu nunca fui igual aos outros garotos, eu nunca tive o mesmo comportamento, a mesma vontade que eles. Eu sabia que era diferente ... A adolescência foi um caos . . . A infância até que foi boa, mas a adolescência e sendo adulto passando isso é um horror. (Roberta, 33 anos).

"Eu nasci uma mulher, eu só percebi que não era uma mulher quando eu vi uma mulher pelada na minha frente" (Priscila, 36 anos).

. . a a minha aparência já foi feminina desde criança. Talvez não feminina, mas uma coisa meio andrógina . . . Eu já era uma menina porque a minha mama já estava crescendo, a minha voz nunca foi grossa, nunca tive muita virilidade ... Eu sempre me isolei, eu não ia no banheiro de jeito nenhum. Quando a minha mama começou a crescer foi um problema seriíssimo porque eu era alvo de piadinhas, é... eu não sei se era macho-fêmea, era um termo bem chulo. O recreio para mim era um tormento. (Aline, 34 anos).

"Eu me olho no espelho e não me reconheço porque eu tenho um pênis no meio das pernas" (Roberta, 33 anos).

Esta percepção de pertencimento ao gênero feminino se dá ao longo da vida através de experiências, práticas, estilos que constituem uma forma específica de relação com o mundo e com o outro. Em alguns casos esta experiência é compartilhada com a família dede a infância, podendo ser reforçada e estimulada pela mãe, pai, irmãos e primos. Em outros casos, ela é vivida de forma traumática, exigindo a ruptura de laços afetivos e familiares, e a reconstrução de uma nova rede de amizade e parentesco. Concordamos com Berenice Bento (2006) que não existe um processo específico de construção das identidades de gênero nos transexuais. Porém, vale ressaltar que na atualidade esta prática ainda está totalmente atravessada pela discriminação e pela exclusão.

\section{Sexualidades}

Em geral, no início dos atendimentos e na própria entrevista, as questões relacionadas à sexualidade ficam em segundo plano; o que se destaca é o desejo de obter uma identidade feminina e não necessariamente de ter relações sexuais. É importante destacar que a reivindicação da cirurgia em função de uma mudança de identidade se justifica, sobretudo, pela necessidade de garantia de inteligibilidade social (Bento, 2006). Porém, aos poucos, estas posições se confundem, já que o que se destaca é a vontade de ser vista e desejada "como uma mulher". Sendo assim, é recorrente a explicação de que não se trata de homossexualidade nem de transvestismo e sim de identidade e de desejo heterossexual. No entanto, como afirma Elizabeth Zambrano (2003), muitas vezes as pessoas que se consideram transexuais podem apropriar-se do discurso médico, acionando diferentes fronteiras identitárias somente para satisfazer a confirmação do diagnóstico. Não devemos querer encaixar a transexualidade numa matriz heterossexual, devemos sempre considerar a possibilidade da diversidade do desejo.

"Tive contato mais íntimo de tocar, isso eu tive. Agora de chegar ao ponto de ter relação... não. Nenhum tipo de relação ... O que passa na minha cabeça é que eu não sou homossexual" (Roberta, 33 anos).

Com doze anos comecei a namorar em casa. Eu nunca me relacionei, nem pretendo me relacionar com uma mulher, mesmo que seja lésbica. E esse rapaz que ficou comigo, ele não foi o tipo de cara de me expor como um homossexual. Ele me namorava como se eu fosse uma menina. Era normal, tinha beijo na boca, mas não tinha esse negócio de ficar passando a mão aqui, passando a mão lá. Eu não deixo ninguém tocar no meu pênis de jeito nenhum, até porque eu já não tinha ereção graças a Deus. (Priscila, 36 anos).

Quando chegou a hora [sexo] e viu que eu não era [mulher], ficou meio assim, falou que pensava que eu era outra coisa. Ele não continuou e terminamos o relacionamento ... Se eu disser que nunca tive um relacionamento com um homossexual é mentira, eu tive. Tive e achava que ele era homem. Quando descobri que ele era homossexual foi horrível, aquele caos. Transexual na cabeça desse povo não existe, todo mundo acha que é travesti. (Priscila, 36 anos).

Eu tive um namorado por muito tempo, eu não falei que sou transexual, que sou hermafrodita ele engoliu na boa ... A grande maioria não soube, mesmo tendo relações sexuais. Eu sempre dava uma desculpa em relação à minha genitália para não olhar, pra não tocar. (Aline, 34 anos). 
Falam comigo que sou maluca porque deixei de ter contato real para ter contato na Internet ... Se você é gay tem uma discriminação, quando é transexual parece que é o dobro. Você não tem direito a nada, nada! Você só tem obrigações, obrigação de ficar calado. Uma vez ouvi que sou uma aberração. Eu pirei por causa disso. Eu tinha medo de assumir para as pessoas. (Roberta, 33 anos).

Observamos que muitas delas preferem não ter relações sexuais por não poderem se apresentar como transexuais. Algumas iniciam um relacionamento e o interrompem por medo da reação do parceiro. Outras dizem que são hermafroditas ou, inicialmente, se apresentam como mulheres que "possuem um problema na genitália". E ainda outras revelam a sua condição e constroem uma vida afetiva e sexual satisfatória. A dúvida sobre como se apresentar, o que dizer e o medo do preconceito são quase que inerentes a esta condição.

\section{Dificuldades profissionais}

Apesar da grande dificuldade de inserção no mercado de trabalho formal, devido a problemas de documentação, a maioria delas tem uma atividade profissional. Das pacientes entrevistadas, duas são cabeleireiras, duas costureiras, duas se prostituem, uma foi dançarina na Europa e no momento é vitrinista e camelô, uma é esteticista, uma é empregada doméstica, uma é estudante universitária e operadora de telemarketing e três relatam não ter profissão.

“. . . eu nunca trabalhei de carteira assinada, só faço bicos . . . Eles não me consideraram apta para exercer a função por causa disso (transexualismo) sendo que já estava tudo pronto para assinar minha carteira. Eu fui discriminada" (Roberta, 33 anos).

"As pessoas no meu trabalho pensam que eu sou uma mulher, não sabem da minha condição" (Aline, 34 anos).

\section{Mudança da identidade civil}

Como já dito, todas as pacientes se apresentam por um nome feminino e, por isso mesmo, têm problemas em relação a sua documentação. São vários os constrangimentos provocados por esta situação, o principal deles profissional, mas também foram referidos problemas no local de estudo, na obtenção de plano e saúde, na solicitação de crédito, entre outros. Quase a totalidade deste grupo deseja entrar com processo na justiça solicitando a mudança do nome após a cirurgia. Uma delas já conseguiu judicialmente a alteração para um nome considerado ambíguo (acrescentando um "e") antes de ter sido operada. É importante esclarecer que já existe jurisprudência para a troca de nome de transgêneros no Brasil, porém per- manece uma discussão sobre a possibilidade da mudança do gênero na certidão de nascimento.

"O nome é sempre uma restrição horrível, mas eu tiro de letra" (Priscila, 36 anos).

\begin{abstract}
Aparentemente, eu não poderia ter um nome masculino e ter uma vida normal. Então foi um consenso na minha adolescência que eu teria que mudar a minha documentação. Por que, como eu poderia trabalhar, ter uma vida normal, tendo um nome masculino e um aspecto feminino? Então, para fugir do preconceito que iria acontecer foi que, graças a minha família, a gente conseguiu a mudança de documentação, e hoje eu sou Aline. Ainda bem, porque graças a isso hoje eu tenho um bom emprego, eu trabalho numa empresa, ninguém na empresa sabe nem desconfia. (Aline, 34 anos).
\end{abstract}

Consideramos a possibilidade de mudança de nome como sendo um processo fundamental na construção e redefinição do gênero. Não tem sentido o reconhecimento do tratamento cirúrgico e das modificações corporais se estas não forem acompanhadas pela mudança do registro civil. De acordo com Zambrano (2003), a permissão para a troca de nome e sexo no registro civil, independentemente da realização da cirurgia, resolveria o problema mais agudo da vida cotidiana dos transexuais.

\section{Expectativa em relação à cirurgia de transgenitalização}

A cirurgia é considerada um processo de adequação a uma condição já existente. Apesar de ser, para algumas pessoas, fundamental para o exercício pleno da cidadania e para auto-realização, as pacientes não parecem ter ilusões em relação à solução de todos os seus problemas, nem mesmo uma idéia de que haveria uma mudança subjetiva. A idéia que prevalece para as que desejam realizar a cirurgia é a necessidade de se livrar de uma parte do corpo que não é reconhecido como seu.

A minha expectativa é de uma vida normal, que eu vou conseguir ter uma vida direita. Se eu colocar uma roupa vai ficar direita, a cirurgia vai me deixar normal . . . Eu sei que não vou ter a sensibilidade de uma mulher, prazer eu sei que eu não vou ter, vai ter alguma possibilidade porque tem algumas terminações nervosas . . . Mas meu caso não é esse, eu tô preocupada com a feminilidade. Para mim o lugar certo de mexer é dentro da cabeça, mas o único jeito é mexer na parte genital. (Priscila, 36 anos).

Sentimentalmente eu acho que vai mudar muito. Eu vou poder, eu tenho tanta vontade de ser alguém, de me entregar a alguém de verdade. Mas eu não tenho essa liberdade. Eu não tenho esse direito ainda . . . Eu acho que a adequação sexual no meu caso vai ser a cereja que falta no bolo. (Aline, 34 anos). 
Eu tenho consciência de que eu nunca vou ser uma mulher completa. Mas só de tirar [o pênis] eu já vou me sentir mais segura diante das pessoas ... Ser uma mulher para mim é estar integrada na sociedade, podendo me assumir para os outros. (Carla, 27 anos).

De todas as pacientes acompanhadas, tivemos um relato quanto à razão de uma desistência da cirurgia.

\begin{abstract}
Não vou fazer mais a cirurgia porque sou soropositivo há três anos. E isso interfere na cirurgia ... Dentro desse tempo que eu fiquei [no Programa] e descobri que a cirurgia não poderia ser realizada, foi quando eu me liberei mais pro sexo e pro prazer. E agora estou satisfeita com o meu sexo ... Eu já consegui o que eu queria que era me transformar em uma mulher. Ter os homens que eu quero, ter os heterossexuais. (Gabriela, 25 anos).
\end{abstract}

\section{Pós-operatório}

A primeira paciente a se submeter à cirurgia é moradora de outra cidade e sua possibilidade de vir ao HUCFF para as consultas tanto no pré quanto no pós-operatório era dificultada por seus poucos recursos financeiros. Nos poucos contatos que tivemos com ela no pós-operatório, relatou as dificuldades e constingências da própria internação:

Quando eu estava internada, veio um funcionário do Hospital me perguntando se eu não queria posar para uma revista de mulher nua ganhando uma grana. Meu companheiro ganha dois salários, eu estou sem emprego, mas imagina só se eu quero aparecer desse jeito? Passei minha vida toda para ser mulher e ninguém me ver de jeito diferente e agora essa? Imagina só, tudo que eu quero é ser vista como uma mulher comum. (Luiza, 26 anos).

Meu maior prazer foi poder entrar no banheiro das mulheres e fazer xixi de porta aberta ... As primas de meu companheiro, que nunca souberam direito quem eu era, todas curiosas, ficaram me vendo e eu ali de porta aberta na maior. (Luiza, 26 anos).

A segunda paciente a ser operada relatou, cerca de 45 dias após a cirurgia, que acabara de manter relações sexuais:

Estava morrendo de medo, era um cara que eu tinha acabado de conhecer, não sabia o que ele ia achar e estava com medo pela cirurgia também, se ia doer, se ia arrebentar. Pois foi ótimo, acho que até senti prazer. E depois para convencer o cara sobre minha situação? Ele ficou louco por mim, achou que eu era virgem, só acreditou que eu não era mulher quando mostrei minha carteira de identidade. (Priscila, 36 anos).

Esta paciente necessitou fazer reparos após a cirurgia, algo já esperado neste tipo de procedimento. Já as outras duas, entrevistadas 60 dias após a cirurgia, parece- ram estar bastante satisfeitas com o resultado. Em relação à internação, relatam ter tido problemas com o adiamento da cirurgia em função de questões institucionais (suspensão da cirurgia no dia marcado), porém tiveram um pósoperatório imediato bastante tranqüilo, não precisaram de reparo e não referiram muita dor. Uma delas, que já conseguiu a troca de nome, fez o seguinte comentário:

Estou bem, tive uma ótima recuperação... os médicos foram muito legais e competentes. Acho que a minha vida vai melhorar muito, mas sempre estive consciente de que não era a solução de todos os meus problemas. Esses dias eu até levei um fora. (Marcele, 24 anos).

A outra paciente, que ainda permanece com o nome jurídico masculino, relatou:

Eu emagreci muito, mas acho que é assim mesmo... mas as coisas mudaram bastante, depois de 7 anos eu querendo entrar numa universidade, não conseguia, não tinha coragem... agora eu consegui. Passei no PRO-UNI. Foi engraçado, eu até ri... Quando fui fazer a matrícula, a moça perguntou: -'Roberto, onde está o Roberto?' Eu falei baixinho: -'Está aqui'. Ela ficou espantada, mas respeitou. Eu vou ter que conversar com todos os professores para quando fizerem a chamada me chamarem de Roberta e não Roberto. Isto é muito chato. Pra mim o mais importante agora é conseguir mudar o nome. Acho que vai ser mais fácil, pois já sou operada. Mas lá no Fórum, eu já fui duas vezes, eles tratam a gente muito mal... não tem informação. (Roberta, 33 anos).

As questões relacionadas à diversidade das técnicas cirúrgicas e necessidades de reparos merecem ser avaliadas e aprofundadas. $\mathrm{Na}$ jornada sobre "Transexualidade e Saúde" referida acima, observamos a diversidade de técnicas utilizadas no Brasil, assim como ter uma primeira avaliação de trabalhos científicos dedicados ao tema. Alguns centros parecem já ter uma casuística relevante que permitam o estabelecimento de protocolos cirúrgicos. Porém, concordamos com a deliberação da jornada de que a incorporação dos procedimentos cirúrgicos de redesignação sexual na tabela do Sistema Único de Saúde deve ficar restrita a Centros de Referência de Assistência Interdisciplinares a pacientes transexuais credenciado pelo Ministério da Saúde.

A partir desta análise, nos aproximamos um pouco da experiência transexual e observamos a importância da constituição de serviços interdisciplinares. Como a demanda é a realização do tratamento cirúrgico, achamos importante estabelecer um tempo para a confirmação desta decisão, como também para o esclarecimento de todas as questões implicadas. Nesta conjuntura, o atendimento psiquiátrico para a confirmação do diagnóstico de transexualismo tem sido um dispositivo de cuidado para a realização da cirurgia, no entanto, sabemos que 
este mesmo diagnóstico é também um vetor de patologização e de estigma, o qual muitas vezes acaba por atribuir uma patologia ao paciente sem questionar as questões históricas, políticas e subjetivas de psiquiatrização da condição transexual. Além disso, fica claro que esta condição de transgênero não significa nenhuma incapacidade mental, sendo que a maioria das pessoas tem total condição de exercer a autonomia de decidir sobre o seu próprio corpo.

Para concluir, consideramos que, nesta conjuntura, a cirurgia de transgenitalização associada ao diagnóstico de transexualismo exigido pela resolução do CFM possibilitou a institucionalização deste debate na rede pública de saúde e, sobretudo, permitiu a transexuais que vivem em condições de extrema vulnerabilidade terem acesso ao tratamento. Porém, isto não quer dizer que esta resolução não deva ser discutida e problematizada, já que o que importa é o reconhecimento de uma situação de intenso sofrimento, a qual não necessariamente se traduz num diagnóstico psiquiátrico. Se o gênero não é uma essência, mas um devir, os seus destinos dependem dos atores políticos e clínicos implicados, e as possibilidades de subjetivação se fazem de acordo com a contingência histórica em que se apresentam.

\section{Notas}

1. Segundo Deleuze, um dispositivo "é uma espécie de novelo ou meada, um conjunto multilinear. É composto por linhas de natureza diferente e essas linhas do dispositivo não abarcam nem delimitam sistemas homogêneos por sua própria conta (o objeto, o sujeito, a linguagem), mas seguem direções diferentes, formam processos sempre em desequilíbrio, e essas linhas tanto se aproximam como se afastam uma das outras. Cada uma está quebrada e submetida a variações de direção (bifurcada, enforquilhada), submetidaa derivações. Os objetos visíveis, as enunciações formuláveis, as forças em exercício, os sujeitos numa determinada posição, são como que vetores ou tensores. Dessa maneira, as três grandes instâncias que Foucault distingue sucessivamente (Saber, Poder e Subjetividade) não possuem, de modo definitivo, contornos definitivos; são antes cadeias de variáveis relacionadas entre si. Deleuze, G. (1990). O que é um dispositivo? Retirado em 05 jun. 2007, de http://www.unb.br/fe/tef/filoesco/foucault/

2. Para um maior aprofundamento do tema, ver comentário da autora sobre a vida de David Reimer no texto "Doing justive to someone: Sex reassignment and allegories of transsexuality" (Butler, 2004). Trata-se de uma história trágica e triste que se tornou conhecida através do livro de John Colapinto - "Como a natureza o fez, o menino que foi criado como uma menina" e que foi amplamente divulgado pela mídia e por vários jornais populares, médicos e psicológicos na década de sessenta e setenta. A autora demonstra como o caso de David foi amplamente utilizado no debate sobre intersexualidade e transexualidade passando a ser palco de uma disputa ferrenha entre as teorias da construção social do gênero de John Money e as teorias essencialistas do sexo biológico de Milton Diamond, demostrando, mais uma vez, como a rigidez dos sistemas de sexo-gênero tornam vidas impossíveis de ser vividas.

\section{Referências}

Arán, M. (2006). A transexualidade e a gramática normativa do sistema sexo-gênero. Revista Ágora-Estudos em Teoria Psicanalítica, 9(1).

Arán, M., \& Peixoto, C. A., Jr. (2007). Subversões do desejo: Sobre gênero e subjetividade em Judith Butler. Cadernos Pagu, Revista Semestral do Núcleo de Estudos de Gênero-Pagu/Unicamp, 28.

Benjamin, H. (1999). The transsexual phenomenon. New York: Julian Press. (Original publicado em 1966)

Bento, B. (2006). A reinvenção do corpo. Sexualidade e gênero na experiência transexual. Rio de Janeiro, RJ: Garamond.

Lionço, T. (2006). Um olhar sobre a transexualidade a partir da perspectiva da tensionalidade somato-psíquica. Tese de Doutorado não-publicada, Instituto de Psicologia da Universidade de Brasília, DF.

Butler, J. (1993). Bodies that matter: On the discursive limits of "sex". Nova York: British Library.

Butler, J. (2003). Problemas de gênero. Feminismo e subversão da identidade. Rio de Janeiro, RJ: Civilização Brasileira.

Butler, J. (2004). Undoing gender. Nova York: Routledge.

Calligaris, C. (1989). Introdução a uma clínica diferencial das psicoses. Porto Alegre, RS: Artes Médicas.

Castel, P. (2003). La métamorphose impensable. Essai sur le transsexualisme et l'identité personnelle. Paris: Galimard.

Chiland, C. (2003). Le transexulisme. Que sais-je? Paris: Puf.

Czermark, M. (1982). 'Précisions sur la clinique du transsexualisme'. Le Discours Psychanalytique, 3, 16-22.

Conselho Federal de Medicina. (1997, 19 set.). Resolução no. 1482 de novembro de 1997. Diário Oficial da União, Brasília, DF.

Conselho Federal de Medicina. (2002, 02 dez.). Resolução no. 1652 de maio de 2002. Diário Oficial da União, Brasília, DF.

Dor, J. (1991). Transexualismo e o sexo dos anjos. In J. Dor. Estruturas e perversões. Porto Alegre, RS: Artes Médicas.

Foucault, M. (1993). História da sexualidade I. A vontade de saber. Rio de Janeiro, RJ: Graal. (Original publicado em 1990)

Foucault, M. (1999). Les anormaux. Cours au Collège de France (1974-1975). Paris: Gallimard.

Frignet, H. (2000). O transexualismo. Rio de Janeiro, RJ: Companhia de Freud.

Frignet, H. (1999). Identité sexuelle et transexualisme. Logos et Anankè, Revue de Psychanalyse et de Psychopathologie, 1, 8396.

I Jornada Nacional sobre Transexualidade e Assistência Pública no Brasil. (2005). Relatório Final. Retirado em jan. 2006 de http:/ /www.ims.uerj.br/transexualidadesaude/

Murta, D. (2007). A psiquiatrização da transexualidade: Uma análise sobre os efeitos do diagnóstico de transtorno de identidade de gênero nas práticas de saúde. Dissertação de Mestrado não-publicada, Universidade Estadual do Rio de Janeiro, RJ.

Peixoto, C. A., Jr. (2004). Sujeição e singularidade nos processos de subjetivação. Revista Ágora - Estudos em Teoria Psicanalítica, 7(1), 23-38.

Stoller, R. J. (1982). A experiência transexual. Rio de Janeiro, RJ: Imago.

Zambrano, E. (2003). Trocando os documentos: Um estudo antropológico sobre a cirurgia de troca de sexo. Dissertação de Mestrado não-publicada, Instituto de Filosofia e Ciências Humanas, Universidade Federal do Rio Grande do Sul, Porto Alegre, RS. 
Márcia Arán é Psicóloga pela Universidade de Caxias do Sul, Mestre e Doutora em Saúde Coletiva pela Universidade do Estado do Rio de Janeiro (UERJ), com

Doutorado- Sanduíche pelo Centre de Recherche Medecine, Sciences, Sante et Societe. É professora do Instituto de Medicina Social da UERJ. Endereço para correspondência: Universidade do Estado do Rio de Janeiro, Instituto de Medicina Social, Rua São

Francisco Xavier, 524, Pavilhão João Lyra Filho, $7^{\circ}$ andar, Bloco D e E, Maracanã, Rio de Janeiro, RJ, 20559900. Tel.: (21) 25 877303; Ramal: 306; Fax: (21) 22641142. marciaaran@terra.com.br

Sérgio Zaidhaft é Psiquiatra, Coordenador da Comissão de Bioética do Hospital Universitário Clementino Fraga Filho (HUCFF) e Professor da Faculdade de Medicina da Universidade Federal do Rio de Janeiro (UFRJ). Endereço para correspondência: Hospital Universitário Clementino Fraga Filho, Av. Brigadeiro Trompowski, s/ n, Ilha do Fundão, Rio de Janeiro, RJ, 21941-590. Tel.:

(21) 25626013 szaidhaft@hucffufrj.br

Daniela Murta é Psicóloga pela UFRJ, Mestre e Doutoranda em Saúde Coletiva (Ciências Humanas e Saúde) pela UERJ. Endereço para correspondência: Universidade do Estado do Rio de Janeiro, Instituto de Medicina Social, Rua São Francisco Xavier, 524,

Pavilhão João Lyra Filho, $7^{\circ}$ andar, Bloco D e E, Maracanã, Rio de Janeiro, RJ, 20559-900. Tel.: (21) 25 877303; Ramal: 306; Fax: (21) 22641142.

Transexualidade: Corpo, Subjetividade e Saúde Coletiva Márcia Ramos Arán, Sérgio Zaidhaft e Daniela Murta

Recebido: 14/03/2007

$1^{a}$ revisão: 05/07/2007

Aceite final: 19/09/2007 